\title{
Motivation to English Academic Writing: Chinese Students' Literacy Autobiography
}

\author{
Yamin Qian \\ School of English and Education, Guangdong University of Foreign Studies, China
}

\begin{abstract}
This study looks at literacy as a site of power in which some forms of literacy practices have more power. Such power relations is even more complicated in English as a foreign language context, where school literacy, family literacy, and English language come into the picture. Many studies have explored different research methods to examine language learners' voices in literacy practices, while literacy autobiography (LA) is not frequently used. LA is a reflective, first-person narrative of personal engagement in literacy practices. Through the LAs from a group of third-year university students in China, this qualitative case study examines motivation to in-school writing in general, their L1 and L2 in- and out-of-school writing experiences in particular. The main dataset includes 25 participants' LAs; critical discourse analysis was used for data analysis. The findings suggest that their motivation to English academic writing is closely intertwined with their L1 academic writing, that it is the pedagogies employed in both L1 and L2 in-school writing that has affected their engagement, and that EFL students' border-crossing experiences between both temporal and spatial spaces have shaped their engagement in writing. More important, demotivated students are not necessarily slow students in writing classes.
\end{abstract}

Index Terms — literacy autobiography, motivation to EFL writing, disengagement, critical literacy

\section{INTRODUCTION}

L2 motivation has been the focus of study for at least three decades, while very few studies explored L2 writing motivation (Lee, Yu, \& Liu, 2018), and even fewer explored EFL writing motivation. While it is widely acknowledged that motivation is subject to change to due the dynamic interaction of self and context ( Lee, et al, 2018; Oldfather \& Shanahan, 2007; Takač \& Berka, 2014). Explorations in English Language and Linguistics, 2(2), 77-103.), there needs more studies understanding EFL students' negotiation of self in EFL writing contexts. For this purpose, this study aims to explore a group of Chinese EFL university students' experiences in their past writing classes, and how this experiences affected their movation to English academic writing.

Although fewer studies discussed the causes of demotivation to L2 writing, a larger group of scholars, both international and Chinese, focused mainly on teaching pedagogies (Lee et al., 2018), some discussions focused on strategies EFL students applied to promote their writing motivation (Hui \& Ma, 2012; Hui \& Chen, 2013), which still provide important insights.

The discussions on teaching pedagogies include many explorations of new teaching methods, such as (1) integrating multiple language skills in the writing process (Chen \& Xiao, 2012), (2) unfolding the writing process (Yan \& Ge, 2011, Zhao, Ao \& Zhou, 2012), (3) designing situationally interesting writing tasks (Chen, Guan, Yu, \& Yang, 2016), and (4) including an extended internet writing space (Yu, Qi, \& Guo, 2012; Wang \& Zhang, 2012; Wang \& Xuan, 2010). And more importantly, some studies (Ai, 2015; Canagarajah, 2015) explored dialogic models of teaching which encourage more interactive contacts between students and teachers, in attempt to further promote students' motivation. These pedagogical discussions reveal the multiple layers of writing motivation, which include language skills, teachers' practice in class, writing spaces and a dialogic modal of teaching. In particular, tt also implies that L2 writing motivation can be affected by writing contexts in the past and present.

Some studies explored contextual factors affecting EFL students' motivation to academic writing (Badiozaman, 2012; Lee et al., 2018; Lo \& Hyland, 2007; Ren, 2017; Tran, 2007). Tran (2007) in a questionnaire study on 30 Vietnamese university students found that EFL students could write with more passion and independence when they have a sense of authorship in their act of writing in a foreign language. Badiozaman (2012) in a qualitative study on a group of Maylasian instructors and university students found that students' sense of self-concept, writing motivation, and institutional learning cultures are dynamically linked in the past and present. Lee et al. (2018) in their survey study of 1395 secondary students found that language proficiency and grade could significantly affect writing motivation. Students at higher grade were less motivated than those in lower grade, due to the pressure from standardized examinations and test-oritented learning culture. Ren (2017) in his study on a group of Chinese university students found that the students' motivation at the beginning and the end of a semester changed, the reasons of which were largely due to sociocultural factors such as teachers, students and teaching beliefs in a writing class. These studies imply one important point: students' motivation of writing can be closely linked to the sociocultural contexts of academic writing programs. 
Many studies explored linguistic factors that affect students' writing motivation (Troika, Shankland, \& Wolbers, 2012). It is understandable that linguistic factors play a faily important role in the focal studies, yet two interesting studies may cast some further thoughts. Tessema (2012) in a qualitative study on an group of Ethiopian university instructors and students found that their percpetion of demotivation causes varied. While the instructors believed that it was because of the students' lack of requisite skills, the students believed that it was the instructors' failure to engage them. Similar disparity was also found from another study. Asadifard and Koosha (2013) investigated a group of Iranian instructors and university students on their perpection of reluctance to English academic writing. The study found that the instructors believed the reluctance was due to task difficulties while the students believed it was lack of readership.

While these aforementioned studies have proved the complicacy of motivation issue, it also reveals that both contextual and linguistic factors are more likely intertwined. While linguistic factors are undoubtedly significant, contexts deserve equal attention. In particular, the contexts in which EFL students are embedded are of particular importance because of its unique sociocultural and institutional circumstances. However, there are fewer studies in attempts to understand how contexts affect EFL students' Englishh academic writing motivation, even fewer discussed Chinese EFL students' contextual factors (Lee et al., 2018). What's more, most studes on the focal issue used questionnaire, very few used students' narratives, which will be explained in the following section.

\section{A. Literacy Autobiography as One Research Method}

Literacy autobiography (LA) is learners' reflective narratives of their personal engagement in literacy practices. It is an effective tool to understand language users' sense-making journey of their literacy experiences (Ai, 2015; Bell, 1995; Canagarajah, 2015; Edwards, 2010; Gardner, 2018; Rose i Solé; 2004; Steinman, 2007). Through the reflective narratives, learners show their sense-making journey about the in- and out-of-school literacy (Gardner, 2018), L1 and L2 practices (Ai, 2015; Canagarajah, 2015; Steinman, 2007), and their identity construction as a student writer (Ai, 2015).

LA can facilitate not only learners' but also instructors' sense-making process. Instructors can also have insights of the process in order to reflect and adjust their pedagogical implementations. In Canagarajah's (2015) study, the LAs from an ESL student informed the instructor of the journey that the student underwent a dialogic pedagogy. These studies have cast important insights on the use of LA to understand both the learners' journey and instructor's pedagogical decisions.

In the limited number of studies on EFL students' writing motivation, some studies used questionnaire method (Asadifard \& Koosa, 2013; Hui \& Cheng, 2013; Hui \& Ma, 2012; Lee, Yu, \& Liu, 2018; Ren, 2017; Wang, Li, Chen, 2009), some used semi-structured interviews (Tessema, 2012; Troia, Shankland \& Wolbers, 2012; Zhang \& Hyland, 2018), and some studies used mixed methods such as interview and questionnaire (Badiozaman, 2012; Qin, \& Yang, 2015; Wang, \& Zhang, 2012). Very few studies used students' literacy autobiography to understand students' L2 writing motivation.

\section{B. Significance of This Study}

This study explores how a group of Chinese EFL students perceived their lower motivation to English academic writing. This study makes its contribution to the studies of EFL learners' English writing motivation. By looking at students' LA, this study attempts to explore students' sense-making process of their English writing motivation. This study contributes itself at two aspects: (1) it explores contextual factors that cause Chinese EFL students' English writing motivation; (2) it employs LA as a major data source for the focal issue.

\section{METHOD}

Since this study discusses EFL participants' motivation to English academic writing, it is necessary to know more about the participants' general background and their English language proficiency. This group of participants were from different provinces of China, yet the majority were from the Southern province in which the university locates. This university has a reputation for its English language teaching and research for decades, therefore students from this university have higher level of English language proficiency compared to students from other universities.

This research was based on an 18-week Advanced Academic Writing course offered to a group of third-year university students at a Southern University in China in 2016. The main data set was from the course, Writing a Book Review, offered by the researcher/instructor. The participants were from English and Education program, which prepares university students to become an English language teacher in K-12 contexts. Students in this program take courses on both English language and Educational theories. Data included the participants' LAs ( $\mathrm{N}=25)$, and a questionnaire $(\mathrm{N}=89)$ at the end of the semester. The 89 questionnaire were from the four classes that the instructor taught in 2016, and the 25 LAs were from one class, randomly selected out of the four classes.

LA was the first writing assignment. I, as the instructor, read my LA to the participants, sharing with them my experiences with in-school writing. Since one purpose of this assignment was to understand how both L1 and L2 academic writing courses influenced their engagement, there were no specific requirements in terms of the length and contents. I did not specify whether this LA was about their L1 or L2 writing, nor about in-school writing or out-of-school writing, yet they were specifically told that they should write in English since this was an English 
academic writing course. One week later, the participants submitted their LAs. A questionnaire was designed in order to understand the participants' engagement in academic writing, which is a tool frequently used by other studies on the focal issue (Lee, 2017). Thematic analysis method was used to analyze the 25 LAs in order to search for contextual factors that the participants claimed to have an impact on their L2 writing motivation.

\section{FINDINGS}

Both the questionnaire and the LAs suggest that the participants' experiences in school writing education is also a process of their understanding and negotiating with the logics of practices in school writing contexts. Specifically, the participants were found adapting to various school writing programs in the past and the present, meanwhile in out-school writing they were more active to construct their logics of practices. Second, those participants claimed demotivated in school writing were not necessarily slow students. The test-oriented writing education at high school disrecognized the participants' previous learning experiences and skills, yet they succeeded in writing for tests.

\section{A. Adapting to School Writing Programs}

The findings suggest that the school writing programs at different stages (i.e., primary, and secondary) had distinct practices. At elementary and junior high school, school writing encouraged students to connect their out-school and previous school writing experience with the current practice. The participants felt strongly motivated since such practice empowered them to share their personal life. As \#6 participant said

Everything happened in my life was wrote down in my dairy. We handed in the diary every morning and in afternoon we got the dairy back with a mark on it. I think it is the happiest time of writing in my whole life because I can write down anything I want in my diary.

And the language skills they learned were also to express their 'whole life', as \#10 participant said,

When I was in primary school, I learned to write some simple sentences, short paragraphs, and then short passages.... For example, describing one significant person or place, narrating my stories, or portraying my dream. ... Writing made us feel enchanted.

Such writing practice was also found corresponding to their family literacy practice, as \#9 participant said,

I was required to keep a diary everyday by my grandmother, who used to be a famous Chinese teacher in my hometown. After finishing my homework, I had to write about something interesting during my school time. ...All of the diaries have still been treasured since now for they always remind me of my own story filling with laughter and tears.

These three exerpts showed a strong connection between school writing and out-school writing, and also between school life and out-school life. However, school writing programs started to be more test-oriented at senior high school, which appeared distinct from their previous writing experiences and their out-school learning experiences. This change also caused a new perspective on school writing. As \#1 participant said, '... writing has become my task, my assignment, my burden'. The change involves more than writing skills, but also the culture of a writing class: the interactions between students and teachers. As \#8 participant vividly explained her experiences in such a writing class,

I still remember that day my Chinese teacher Mrs. Li read my composition in front of the whole class, as Mr.Chen usually did in primary school. But this time was different, she read it out as a bad example. The title of the composition was Call for__ first we had to complete the title then write an essay. I chose Call for loneliness as my topic, but I got $\mathrm{C}$ minus at the end. After Mrs. Li finished reading, she asked the students if they knew what was wrong with my composition. 'Class, remember, the idea of a composition is the most important part. You have to figure out why the test providers design this kind of topic and what kind of composition they want to read.' ... 'Clearly, the title is Call for___, you should write something good, something desires us to pursue, like love, social ethics or honesty, right.' ..., she ... continued: 'That's why I fail you, Liz. I admit that the language is pretty good, but don't you wander from the subject again. Loneliness is not what your examiner want!' 'But I think...' I tried to defended, but her words got a big laugh, and no one heard me.

Liz, \#8 participant in this study, called this experience "humiliating" and admitted that it still hurt when she wrote about this moment. As Lee et al. (2018) has suggested the school culture of writing at secondary school can be a possible reason why EFL students feel demotivated when they reach higher grader, this study verified this suggestion. And further, this study suggests that such school culture, to a certain extent, can bring learners a completely opposite feeling toward writing: it may also bring learners a sense of shame.

Interestingly, their LAs showed enthusiastic engagement in out-school writing. First, their out- school writing showed their abilities to engage in a variety of complicated writing practices such as poems, songs, love stories and blogs. As \#1 participant said, 'May be I just like writing diary because there is no need to worry about what I should write and how good or bad my writing is'. \#2 participant also said, 'I also liked to write down some little poems and copy some lyrics of my favorite songs in [sic] my blog'. \#6 participant echoed, 'Absolutely it has nothing to do with logic or organization. The most important thing of writing is to turn my spoken language to written form, and as fluent as possible'.

Also, their out-school writing was complicated and sophisticated. Not only it was used to express their feelings, it was also used to solve issues in their life. As \#8 participant said, 
In last summer vacation I was undergoing a painful break-up. Like a color bubble bursts of in the sun, I found myself standing on a messy life with a heap of memories at my feet, ripped into pieces. Talking to people was not my style, this was why I put pen to paper, after several years, again.

As \#15 participant explained how writing solved her family issues.

And recently, I found out one big function of writing is to solve problems between my mother and me. I think every mother and daughter have problems or disagreements sometimes which doesn't mean there are bad relationships between them. So do we. ... More importantly, it really strengthened my love towards my mother. Writing gave me an official opportunity to reflect my life, and to be a spectator to feel the deepest love from mother to daughter.

The participants felt disengaged in secondary school writing when they found the school culture and teaching pedagogy became test-oriented. They became more interested in out-school writing since they felt it was more personal, creative and interactive, yet they also realized that this space also has its rules which could affect their writing practice. Their out- school writing was mostly on Weibo, a public social network website for Chinese people to share their opinions. For every message, Weibo users can only write a message within 140 words, with no specific requirements on genre and topics. Although most participants claimed active participation on Weibo, one participant explained her experiences on Weibo.

As I don't have to write compositions for Chinese exams anymore, I gave up writing and enjoyed in sending microblogs with 140 words limit.... One ordinary night, I suddenly came across an idea. I found a paper and pen, and began to design how I should write. It was so strange that I can't think of any long paragraph. All I can get is no more than 140 words.

It seems that the participants' experiences in school writing was a process of following two different types of logics of practices: during the elementary and junior high school, school writing was to introduce their voices into classrooms, while in senior high school, school writing became more test-oriented, and for writing for test-raters. In response to such a more restrictive function of writing, the participants seemed to explore out-school writing spaces; however, it does not imply that they failed the test-oriented school writing at high school. The following explains their frustration and also strategies they adopt in order to excel.

\section{B. Lack of Motivation Yet Still Made It}

The test-oriented high school writing required the participants to write in a highly structured format which usually had a designated opinion, sets of recommended sentences and vocabulary, because it may help them to obtain a higher score. Although aware of the purposes, the participants showed strong reluctance. As \#3 participant said, "The formulaic writing always makes me feel I am forced to write, but not because I love to write".

This pedagogy conveyed an impression to the participants that argumentative writing was not just disconnected from their personal life, but also lacked vitality. (As instructors of academic writing, we know it is not true.) As \#4 participant said, 'Each article is all in the same key. I don't like this kind of writing'. \# 15 participant also said,

... those book reports, reviews, compositions, essays or researches took over diary to become my main writing experience. They were no longer the witness of innocence simply, but the impassive assignments, with the pressure of academy. I wrote for my teacher, for high score. Such kind of writing trapped me into the fear and alarm.

Although most participants showed their reluctance, even 'fear' toward such writing, the participants realized the importance of high school writing: it has been one of the mandatory writing tasks in both L1 and L2 for an entrance examination to university. Therefore, they managed to adjust since it can obtain symbolic capital important for further education. One common belief they held regarding their reluctance to write was that they lack of logical reasoning skills. As \#11 participant explained,

However, I realized that it was a process to teach me developing my writing logic.For instance, I learnt how to develop a whole story in paper and pay attention to the point. When I was writing, all my emotion should be based on some specific things like my experience or what I saw.

Also, the participants started to learn how to write for teachers and test-raters, as \#8 participant explained,

I became careful with what I think and what I write, measuring the intention behind the paper as well as pandering to what teachers liked. I wrote for test and I wanted high grade, so I stared imitating the idea of news review, model essays and other materials. Turned out, this method was the safest one.

As instructors and researchers of academic writing, we all know the importance of writing for audience, and are familiar with the pedagogies enhancing our students such skills. Yet, from the participants' perception, it may not be what we wish it should be.

Also, some pedagogies caused a sense of uneasiness. As \# 10 participant said,

The teacher taught us a lot about what a high-score composition should be like.... we learned what kind of theme, format and writing techniques would be more appreciated, and we learned the ways to move teachers who would 
grade our papers. In order to get a higher mark, I applied those 'devices' mechanically to my compositions, and just as what Han $\operatorname{Han}^{1}$ said, I told lies.

\#3 participant pointed out such pedagogy showed an opposite practice from their belief of writing, "The more devices and strategies of writing I learnt [sic] in classes, the more I felt I was getting farther and farther from WRITING. That's somewhat disappointing to me.". Some participants questioned such pedagogy as it appeared more like plagiarism. As \#11 participant said, '... [the] teacher often let us recite some passage so that we can use them in the exams. It made me very uncomfortable, just like I steal someone's belongings. I don't like such writing which lost its meaning'.

It is important to point out, however, that the participants who claimed disengaged in argumentative writing were not necessarily under-performing student. Quite a few participants were top students in their high school. What \#10 participant said can effectively support this point, 'I didn't like writing at all at the beginning, though my Chinese teachers all thought I was good at it'.

Although reluctant, the participants called argumentative writing "real writing" (\#2 participant) since this genre was important in school and national assessment. Obtaining a higher score became a sole goal. As \#13 participant said, 'Whenever my composition got a decent score, I would feel great... At that time, the joy of writing lied in having a good score on test paper.'

Such test-oriented writing culture caused students to feel powerless. As \#2 participant said, ‘...until I went into high school, writing took up a big percentage in the college entrance examination, whether English writing or Chinese writing. I was depressed but I can do nothing else'. More importantly, after the three year learning in such institutional culture, the participants realized that they need to regain skills to express their true self. As \#4 participant explained, 'now I am at university, I could freely express my opinions, but I forgot how to express my voices '

To sum up, the participants' demotivation to school writing could be interpreted as a form of resistance to the assessment-oriented pedagogy, while they also accepted the dominant ideology and pedagogy.

\section{DISCUSSION AND IMPLICATIONS}

The findings resonate with other studies that literacy autobiography can reveal the depth of language learners' negotiation and identity construction in writing contexts (Ai, 2015; Canagarajah, 2015; Ros i Solé, 2004). It can be also an effective method to understand EFL students' writing motivation. In this study, the LAs disclosed the participants' voices which have been seldom heard of from other data sources, adding substantial insights to what the questionnaire revealed.

The findings are based on a small group of EFL learners' writing experiences, and the main dataset is LAs and a questionnaire, which may not be generalizable for broader groups. However, this study does provide insights in regard to the issue of EFL learners' writing motivation.

The participants' LAs reveal the complexity of EFL writing motivation. First of all, due to the unique sociocultural contexts EFL students usually situate, their motivation to English academic writing is closely intertwined with their L1 academic writing. In other words, language differences (i.e., L1 and Foreign langauge) do not always make learners' experiences distinct in school writing. This finding echoes the current studies that EFL/ESL students' writing motivation is more thant their English language proficiencies (Chen, 2002; Cummings, Kim, \& Eouzanzoui, 2007), and that student writers' prior L1 and L2 writing experiences can have significant impacts on the development of writing abilities (Kobayashi \& Rinnert, 2008). This study makes its contributing by pointing out that it is more likely because of the discourse and pedagogy of school writing that causes the disengagement. The disengagement is not always a result of lower English language proficiency. Rather, the test-oriented pedagogy has shaped in-school writing classes a symbolic space exclusive of previous in-school writing experience, and out-school life in the past and present. Therefore, the participants regarded both L1 and L2 in-school writing one space which is more likely linked to exams, tasks, highly-regulated writing without personal voices.

Secondly, this study makes its contribution by unfolding how the spaces of writing (i.e., school writing vs. out-school writing) in the past and the present play a more significant role in EFL students' engagement in school writing. More specifically, EFL students' border-crossing experiences between both temporal and spatial spaces have shaped their engagement in writing. Although these participants successfully crossed the borders, as they were passed the entrance exame and admitted to the university known for higher requirements of English lagnauge proficiency, their motivation to English writing was not necessarily strong.

Thirdly, the findings also indicate that the boundaries between in-school writing and out-school writing are constantly changing: In-school writing space is once connected to out-school writing, yet later becomes disconnected. Specifically, school eventually becomes a space exclusive of the learners' past and out-school writing practice, with highly patterned writing practices. This space disempowers personal voices, while out-school writing is more dynamic and more inclusive of lived experiences. This finding agrees with Harklau's (2000) research that the temporal space in which learners live can also shape their self-concept which further influences their level of engagement. This finding

\footnotetext{
${ }^{1}$ Han Han is a very popular and successful novelist in China. He has published a few articles on Chinese education system, and also a number of popular novels.
} 
also resonates to current findings that ESL/EFL students' literacy practices in and out of school are more likely to be disconnected, and such disconnection usually disadvantages learners at school performance (Li, 2001).

Fourth, this study argues that the students' disengagement in school writing is not simply a matter of lower English language proficiency and of limited writing strategies; it is actually a resistance to the exclusive nature of in-school writing. Instead of looking at English academic writing differently from Chinese academic writing, academic writing as one in-school language practice in nature share more similirities than diffrences.

Therefore, the most urgent task for teachers and teacher educators is to explore how to link school writing to their lived experiences out of school space and their previous writing history. For EFL teachers, students should be encouraged to express their own voices in argumentative writing. A process writing approach which focuses on revision can be one choice. In the multiple-drafted writing process, learners take their time to negotiate with the text, with their peers, and with their instructor, from which they embark on a dialogic journey to question themselves and to discuss with their readers (i.e. peers and instructors).

However, it is also important to understand the highly-patterned teaching pedagogy which has been dominant in most Chinese high schools. The template-based writing has efficiently promoted students' writing to a standard that ensures for them to attend universities, although this pedagogy has also shown its exclusiveness of students' voices, and eventually decreased students' motivation to write. Thus, the central question is how to introduce argumentative writing as a genre inclusive of students' personal life. Most importantly, the introduction of argumentative writing needs to be connected to learners' previous writing genre (i.e., narrative writing), and their out-of-school writing. While attempts have been made to include learners' voice in the US higher and secondary writing education (Matsuda \& Jeffery, 2012), it is agreed that their voices are from their lived experiences and from both in- and out-of-school spaces in the past and the present. Therefore, teaching pedagogies should explore the dialogic relations between learners' lived experiences in various temporal and spatial space and their academic writing. Studies (De Bernardi \& Antolini, 2007; Klein \& Rose, 2010) suggested that students' interests toward argumentative writing can be effectively promoted when they can write on topics that appear interesting to them, work as groups to share different opinions, and learn to explore information and resources to support their opinions. Therefore, if teachers encourage students to choose topics of their interests, and use students' stories in their writing, students may feel more motivated.

\section{REFERENCES}

[1] Ai, B. (2015). A study of the EFL writing of Chinese learners: A critical narrative. Changing English: Studies in Culture and Education, 22(3), 294-306.

[2] Asadifard, A., \& Koosha, M. (2013). EFL Instructors and Student Writers' Perceptions on Academic Writing Reluctance. Theory and Practice in Language Studies, 3(9), 1572-1578.

[3] Badiozaman, A. (2012). A study on the relationship between Malaysian learners' self-concept in academic writing and their engagement in one higher learning institution. Retrieved on Oct., 20, 2018 from http://mro.massey.ac.nz/handle/10179/4090?show=full.

[4] Bell, J. S. (1995). The Relationship Between L1 and L2 Literacy: Some Complicating Factors. TESOL Quarterly, 29(4), 687-704.

[5] Canagarajah, A. S. (2015). "Blessed in my own way:" Pedagogical affordances for dialogical voice construction in multilingual student writing. Journal of Second Language Writing, 27, 122-139.

[6] Chen, C. H., \& Xiao, H. (2012). An experimental study on the L2 listening and speaking-to-write approach based on memetics. Foreign Language World, 6, 66-73.

[7] Chen, Y., Guan, X. X., Yu L. M., \& Yang, L. R. (2016). The construct Componentiality and Arousal of Situational Interest in L2 Writing. Foreign Languages and Their Teaching, 3, 94-102.

[8] Cumming, A., Kim, T. Y., \& Eouanzoui, K.B. (2007). Motivations for ESL writing improvement in pre-university contexts. In S. Hidi \& P. Boscolo (Eds.), Writing and Motivation (pp. 93-111). Oxford: Elsevier.

[9] De Bernardi, B., \& Antolini, E. (2007). Fostering students' willingness and interest in argumentative writing: an intervention study. In S. Hidi \& P. Boscolo (Eds.), Writing and Motivation (pp. 183-201). Oxford: Elsevier.

[10] Edwards, D. (2010) "Tracing Literacy Journeys: the Use of the Literacy Autobiography in Preservice Teacher Education," Australian Journal of Teacher Education, 34(4), Article 6.

[11] Gardner, P. (2018). Writing and writer identity: The poor relation and the search for voice in 'personal literacy'. Literacy, 52(1), $11-19$.

[12] Ha, P. L. (2009). Strategic, passionate, but academic: Am I allowed in my writing? Journal of English for Academic Purposes, 8 , 134-146.

[13] Harklau, L. (2000). From the "good kids" to the "worst": Representations of English language learners across educational settings. TESOL Quarterly, 34(1), 35-67.

[14] Hui, L. H., \& Chen. L. F. (2013). An re-investigation of university students' strategies of writing motivation, Foreign Languages and Translation, 01, 56-65.

[15] Hui, L. H., \& Ma. S. (2012). A study on the university students' coping strategies and writing motivation, Journal of Inner Mongolia Normal University (Education Science), 01, 44-48.

[16] Klein, P. D., \& Rose, M. A. (2010). Teaching argument and explanation to prepare junior students for writing to learn. Reading Research Quarterly, 45(4), 433-461.

[17] Kobayashi, H., \& Rinnert, C. (2008). Task response and text construction across L1 and L2 writing. Journal of Second Language Writing, 17, 7-29. 
[18] Lee, I. (2017, May). Motivational strategies in EFL writing classes. Keynote speech presented on The Third Beijing Foreign Studies University Open Class on Writing and Pedagogy Conference, Beijing, China.

[19] Lee, I., Yu, S., Liu, Y. (2018). Hong Kong Secondary Students' Motivation in EFL Writing: A survey Study. TESOL Quarterly, 52, 176-187.

[20] Lo, J., \& Hyland, F. (2007). Enhancing students' engagement and motivation in writing: The case of primary students in Hong Kong. Journal of Second Language Writing, 16, 219-237.

[21] Matsuda, P. K., \& Jeffery, J. V. (2012). Voice in student essays. In K. Hyland \& C. S. Guinda (Eds.). Stance and Voice in Written Academic Genres (pp.151-165). Palgrave: Macmillan

[22] Oldfather, P., \& Shanahan, C. H. (2007). A cross case study of writing motivation as empowerment. In S. Hidi \& P. Boscolo (Eds.), Writing and Motivation (pp. 257-279). Oxford: Elsevier.

[23] [23] Ros i Solé, C. (2004). Autobiographical Accounts of L2 Identity Construction in Chicano Literature. Language and Intercultural Communication, 4 (4), 229-241.

[24] Steinman, L. (2007). Literacy autobiographies in a university ESL class. The Canadian Modern Language Review, 63 (4), 563-573.

[25] Takač, V., Berka, O. (2014). Motivation in foreign language learning: A look at type of school environment as a contextual variable. Explorations in English Language and Linguistics, 2(2), 77-103.

[26] Tessema, K. A. (2012). Reluctance to Write Among Students in the Context of an Academic Writing Course in an Ethiopian University. The Asian EFL Journal Quarterly, 14(1),142-176.

[27] Tran, T. L. (2007). Learners' motivation and identity in the Vietnamese EFL writing classroom. English Teaching: Practice and Critique, 6 (1), 151-163.

[28] Wang, N., \& Zhang, H. (2012). A study on internet-based writing motivation and abilities, Computer-Assisted Foreign Language Education in China, 3, 36-41.

[29] Wang, Y., \& Xuan, A. (2010). Social cognitive perspective on Internet L2 Writing, Computer-Assisted Foreign Language Education, 5, 48-52

[30] Yan, J., \& Ge, Y. F. (2011). Applying process writing method to improve non-major university students' writing abilities, Journal of Language and Literature Studies, 4, 108-110.

[31] Yu, Li., Qi, P., \& Guo, P. J. (2012). Teaching Intervention in English Writing on Basis of Digital Writing System, Computer-Assisted Foreign Language Education in China, 4, 17-21.

[32] Zhao,J. K., Ao, L., Zhou, Y. (2012). Effectiveness of A Strategy-focused Instruction in College EFL Writing. Computer-Assisted Foreign Language Education in China, 1, 52-56.

[33] Zhao, C. G. (2013). Measuring authorial voice strength in L2 argumentative writing: The development and validation of an analytic rubric. Language Testing, 2, 201-230.

[34] Zhao, C. G., \& Llosa, L. (2008). Voice in high-stakes L1 academic writing assessment: Implications for L2 writing instruction. Assessing Writing, 3,153-170.

Yamin Qian has received her Ph.D degree at University of Toronto, Canada, in 2012.

She is currently working as an Associate Professor at School of English and Education, Guangdong University of Foreign Studies. Her research interests include, not limited to, EFL academic writing, Bourdieu studies, and critical pedagogy.

Dr. Qian is a journal reviewer for the journals of CCSE (Canada) and Hong Kong Comparative Education. 